\title{
Cambios estructurales y prácticas de movilización política en Argentina. Dos ciclos políticos en perspectiva (1989-2002 y 2003-2015)*
}

Structural Changes and Political Mobilization Practices in Argentina. Two Political Cycles Put into Perspective (1989-2002 and 2003-2015)

Martin Retamozo ${ }^{1, a}$

Universidad Nacional de La Plata, Argentina

martin.retamozo@gmail.com

ORCID: http://orcid.org/0000-0001-8778-7667

Lucia Trujillo ${ }^{2}$

Universidad Nacional de La Plata, Argentina

ORCID: http://orcid.org/0000-0003-4319-1604
DOI: https://doi.org/10.11144/Javeriana.papo23-2.cepm Redalyc: http://www.redalyc.org/articulo.oa $: \mathrm{id}=77757839006$

Fecha de recepción: 28 Noviembre 2017 Fecha de aprobación: 18 Junio 2018 Fecha de publicación: 18 Diciembre 2018

\section{Resumen:}

Este artículo analiza dos ciclos de movilización ocurridos en la Argentina. El primero, ocurrido entre 1989 y 2002 , en el que se registran repertorios de acción clásicos e innovaciones y nuevos actores como respuestas a la situación socioeconómica. Yel segundo, entre el 2003 y el 2015, en un contexto de retorno de lo nacional, popular, estadocéntrico, en el que se evidencia una revitalización de los sindicatos, cambios en las demandas sociales y la forma de movilización. La mirada propuesta incluye la relación entre cambios estructurales y las respuestas de movilización política en ambos ciclos y pone en evidencia las mediaciones que operan entre la estructura y la acción para explicar la dinámica de la contienda.

Palabras clave: Argentina, ciclos políticos, acción colectiva, movilización social.

\section{Abstract:}

This article analyzes two mobilization cycles that took place in Argentina. The first one was between 1989 and 2002, in which classic action repertoires as well as innovations and new actors were observed in reply to the socioeconomic situation. The second cycle took place between 2003 and 2015 in a context of retaking the national, the popular, and seeing the State again as a core. This cycle evinces a reinvigoration of the trade unions, changes in the social demands, and the way how people do mobilizations. Their proposed view points at a new relation between the structural changes and the political mobilization responses in both cycles and shows the mediations between the structure and action in order to explain the dynamics of contention.

Keywords: Argentina, political cycles, collective action, social mobilization.

\section{Introducción}

Hace algunos años, Charles Tilly, una de las máximas referencias en el estudio de la movilización social, se preguntaba

¿qué relaciones sistemáticas existen, si es que existe alguna, entre el cambio social a gran escala y los cambios en la movilización política popular? ¿Qué impacto, si es que tiene alguno, tienen las variadas formas de acción política popular sobre el curso del cambio social a gran escala? (1998, p. 27)

Luego lamentaba que los estudiosos de las prácticas de movilización sociopolítica hayan abandonado la pregunta por el vínculo entre conformación (y disputa) del orden social y las prácticas políticas. Recuperando

Notas de autor:

\footnotetext{
1 Universidad Nacional de La Plata (UNLP), Consejo Nacional de Investigaciones Científicas y Técnicas (Conicet), Argentina

2 Universidad Nacional de La Plata (UNLP), Consejo Nacional de Investigaciones Científicas y Técnicas (Conicet), Argentina

a Autor de correspondencia. Correo electrónico: martin.retamozo@gmail.com
} 
aspectos de este desafío, el objetivo de este artículo es mostrar la relación entre cambios estructurales y prácticas políticas (en particular de acción colectiva y formas de organización sociopolítica) para reconstruir las instancias de mediaciones que ayudan a explicar la dinámica del conflicto fuera de la "visión espasmódica de la historia popular" (Thompson, 1979, p. 62), pero a la vez escapando del desanclaje de la contienda social protagonizada por sectores subalternos de las condiciones materiales en que estos grupos producen y reproducen su vida. Esto implica incluir una concepción de estructuras no deterministas, como la que propone Raymond Williams (1980) y concebirlas tanto constrictoras como habilitantes para la acción (Giddens, 1984). La perspectiva del realismo relacional elaborado por los teóricos del enfoque del proceso político (McAdam, Tarrow y Tilly, 2001) permite reconstruir la trama de interrelaciones que estructuran la dinámica del conflicto y a su vez son estructuradas por la contienda.

régimen social de acumulación

[...] como una matriz de configuración cambiante en cuyo interior se van enlazando diferentes estrategias específicas de acumulación y tácticas diversas para implementarlas, de manera que la acumulación de capital aparece siempre como el resultado contingente de una dialéctica de estructuras y de estrategias. (p. 996. Véase también Nun, 1987)

Estas matrices inciden en la estructuración de las relaciones sociales y son gestionadas por determinado régimen político que produce una serie de gramáticas políticas como resultante de tensiones sociales que, a su vez, son modeladas por ellas. Entre las gramáticas políticas encontramos las plasmadas en instituciones que conducen el conflicto y la acción colectiva por canales institucionalizados a lo largo de décadas de luchas y sedimentados en reglas codificadas legalmente. Pero también un conjunto de gramáticas no institucionalizadas e innovadoras, frecuentemente transitadas por movimientos sociales o de protesta, que emergen cuando los canales institucionalizados son obturados, saturados o no pueden procesar nuevas configuraciones de demandas. Finalmente, resta decir que ambas gramáticas (institucional y extrainstitucional) pueden convivir en un mismo momento político, incluso para los mismos actores que ingresan a diversos "juegos" en momentos distintos del accionar.

El análisis de estos ciclos ayuda a poner en perspectiva histórica (diacrónica y sincrónica) la compleja relación entre aspectos estructurales y respuestas colectivas, así como explicar las dinámicas de la contienda en el país. Este artículo propone focalizar en dos ciclos políticos. El primero, entre 1989 y el 2002, que puede considerarse una larga década neoliberal, será objeto de la segunda sección. El segundo, 2003-2015, de retorno de lo estatal-nacional-popular será foco de la tercera sección. Para la realización de este estudio se utilizaron fuentes estadísticas e indicadores socioeconómicos y laborales para reponer los aspectos estructurales en que se desarrollaron las prácticas de movilización, las cuales fueron sistematizadas a partir de dos proyectos de investigación en curso ${ }^{[1]}$ y la bibliografía especializada.

\section{La larga década de los noventa: el ciclo y sus fases}

El 10 de diciembre de 1983, Raúl Ricardo Alfonsín asumió la presidencia de Argentina, dando fin de esta manera al gobierno autoritario de la dictadura cívico-militar que tomó de facto el poder el 24 de marzo de 1976. Las expectativas en las transiciones a la democracia de los años ochenta encontraron un principio de realidad cuando los problemas para estabilizar variables macroeconómicas se agudizaron en un contexto de crisis de la deuda y generaron un deterioro en las condiciones de vida de los sectores asalariados, como se muestra en la tabla 1 . 
TABLA 1

PBI, inflación, pobreza, desempleo y desigualdad 1980-1989

\begin{tabular}{|c|c|c|c|c|c|}
\hline Año & PBI $\left(^{*}\right)$ & Inflación (*) & Pobreza (***) & Desempleo (***) & Gini (....*) \\
\hline 1980 & 0,7 & 103 & 7,13 & 2,5 & 0,39 \\
\hline 1981 & $-5,2$ & 104,9 & 5,08 & 5,3 & 0,39 \\
\hline 1982 & $-0,7$ & 137,2 & 21,55 & 4,6 & $s / d$ \\
\hline 1983 & 4,3 & 325,8 & $\mathrm{~s} / \mathrm{d}$ & 3,9 & s/d \\
\hline 1984 & 1,6 & 615,5 & $\mathrm{~s} / \mathrm{d}$ & 4,4 & s/d \\
\hline 1985 & 5,2 & 1003,2 & 14,19 & 5,9 & 0,42 \\
\hline 1986 & 6,2 & 50,9 & 10,29 & 5,2 & 0,42 \\
\hline 1987 & 2,7 & 116,5 & 15,74 & 5,7 & s/d \\
\hline 1988 & $-1,1$ & 381,2 & 24,15 & 6,1 & 0,46 \\
\hline 1989 & $-7,2$ & 3611,3 & 38,29 & 7,1 & 0,46 \\
\hline
\end{tabular}

Fuente: Cavallo y Bertolotto (2016), Arakaki (2011), Altimir, Beccaria y González Rosada (2002) y Gasparini (1999) *INDEC

** Inflación verdadera

*** INDEC, GBA-Onda Octubre

**** INDEC, GBA-Onda Octubre, aglomerados urbanos ***** INDEC

Las promesas incumplidas de la democracia en materia social y las condiciones socioeconómicas deterioradas fueron escenario para la respuesta de actores clásico como los sindicatos y los partidos políticos (Di Tella; 1998; Richards, 1997; Rocca Rivarola, 2009). Nos referimos, especialmente, a las huelgas nacionales que decretó la Confederación General del Trabajo (CGT) ${ }^{[2]}$ contra las políticas del gobierno nacional y las últimas internas partidarias del Partido Justicialista (quizás el único periodo en que el movimiento peronista funcionó bajo la gramática partidaria) ${ }^{[3]}$. En esta fase, la contienda política permaneció contenida por los actores del sistema de partidos y sindicatos, aunque con una revitalización de sectores de la sociedad civil, fundamentalmente organizaciones de derechos humanos ${ }^{[4]}$ que atisbaban una regeneración del espacio público (Jelin, 1995). La salida de la dictadura cívico-militar parecía, a pesar de sus dificultades en materia económica, dar lugar a una transición comandada, finalmente, por la normalidad de una democracia representativa luego del desborde de movimientos nacional-populares y gobiernos autoritarios.

Carlos Menem asumió el gobierno el 8 de julio de 1989 en el contexto económico descripto y en un escenario político marcado por acciones de protesta con saqueos a comercios y el retiro anticipado del gobierno de Raúl Alfonsín, cuyo efecto fue el debilitamiento de la oposición partidaria. Las reformas implementadas por Menem apuntaron al desmantelamiento de la matriz sociopolítica estatal-nacional. Para 
autores como Garretón, Cavarozzi, Cleaves, Gereffi y Hartlyn (2004), las configuraciones sociopolíticas entre 1930 y 1980 pueden conceptualizarse como una matriz estatal nacional-popular. Allí, el Estado funciona como mecanismo de coordinación social, en tanto

[...] como un símbolo e institución de unidad, desempeña un papel central, tanto por sus funciones para asignar recursos por medios de políticas sociales y redistributivas, como por la articulación de las demandas sociales. En la mayoría de los casos, la forma más eficaz de acción colectiva es directamente política (de movilizaciones). (Garretón et al., 2004, p. 25)

Asimismo, contiene una orientación a la industrialización por sustitución de importaciones, un cariz nacionalista y la conformación de actores en el terreno de la producción (el trabajo) y las mediaciones sindicales. En Argentina, a diferencia del caso chileno en el que se centra Garretón, la dictadura no desmanteló por completo la matriz (aunque inició el proceso) y fue Carlos Menem el que introdujo cambios sustantivos en el rol del Estado y sus mediaciones, consolidó un proceso de desindustrialización y una inserción subordinada en el proceso de globalización. En particular "en materia de relaciones de trabajo, cambiaron casi todas y cada una de las dimensiones que conformaban el sistema nacional de relaciones laborales" (Novick, 2001, p. 26). Por su parte, el desanclaje de orientaciones nacional-populares del peronismo por parte de Menem produjo un dilema identitario para aquellos sectores políticos y sindicales inscriptos en la matriz plebeya del peronismo ${ }^{[5]}$, la cual el mandatario abandonaba (Martuccelli y Svampa, 1997).

Los resultados económicos y político de los primeros años del gobierno fueron positivos a corto plazo, fundamentalmente por el efecto de control de la inflación que tuvo el plan de la Convertibilidad, que equiparaba por ley el peso argentino al dólar estadounidense (tabla 2). 
TABLA 2

PBI, inflación, pobreza, desempleo y desigualdad 1990-2002

\begin{tabular}{|c|c|c|c|c|c|}
\hline Ańo & PBI $\left(^{*}\right)$ & Inflación (**) & Pobreza $(\cdots \cdot)$ & Desempleo (***) & 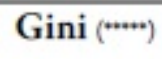 \\
\hline 1990 & $-2,5$ & 2047,7 & $\mathrm{~s} / \mathrm{d}$ & 6,3 & 0,47 \\
\hline 1991 & 9,1 & 178,3 & $\mathrm{~s} / \mathrm{d}$ & 6,0 & 0,46 \\
\hline 1992 & 7,9 & 18,6 & 29,3 & 7,0 & 0,43 \\
\hline 1993 & 8,2 & 10,7 & 27,0 & 9,3 & 0,46 \\
\hline 1994 & 5,8 & 3,6 & 30,0 & 12,1 & 0,45 \\
\hline 1995 & $-2,8$ & 3,2 & 38,0 & 16,6 & 0,46 \\
\hline 1996 & 5,5 & 0,0 & 39,0 & 17,3 & 0,48 \\
\hline 1997 & 8,1 & 0,6 & 37,0 & 13,7 & 0,49 \\
\hline 1998 & 3,9 & 1,2 & 38,0 & 12,4 & 0,49 \\
\hline 1999 & $-3,4$ & $-1,5$ & 38,2 & 13,8 & 0,50 \\
\hline 2000 & $-0,1$ & $-0,9$ & 39,5 & 14,7 & 0,50 \\
\hline 2001 & $-4,4$ & $-1,1$ & 44,0 & 18,3 & 0,51 \\
\hline 2002 & $-10,9$ & 32,9 & 62,0 & 17,8 & 0,54 \\
\hline
\end{tabular}

Fuente: Cavallo y Bertolotto (2016)

* INDEC

** Inflación verdadera, tasa de inflación anual al mes de julio

${ }^{* * *}$ CEDLAS, informe breve, marzo de 2017; datos comparables con base en la nueva

**** INDEC, Onda octubre. Hasta 1994 el relevamiento se realizaba en 25 aglomerados. En octubre de 1995 se incorporaron Concordia, Río Cuarto y Mar del Plata-Batán. En la onda de octubre DE 2002 se incorporaron tres nuevos aglomerados: Viedma-Carmen de Patagones, San Nicolás-Villa Constitución y Rawson-Trelew ***** Cálculos propios con base en la EPH-puntual onda mayo-GBA, INDEC, IPCF

Esta situación, expuesta en los indicadores de la tabla 2, fue el contexto de una primera fase de respuestas políticas de los actores constituidos. Si bien la tendencia del comportamiento del sindicalismo ante el gobierno de Carlos Menem fue mayormente adaptativa o de "supervivencia organizativa" (Murillo, 1997), algunos gremios particularmente afectados por las privatizaciones de las empresas públicas protagonizaron una fase de resistencia a la implementación de las reformas, como las huelgas ferroviarias de 1991 (Gordillo, 2004). Hacia 1992, un conjunto de sindicatos, fundamentalmente estatales (empleados públicos y docentes) convocaron al Congreso de los Trabajadores Argentinos que devendría en una nueva organización obrera: la Central de los Trabajadores Argentinos en 1996 (Armelino, 2012; Retamozo y Morris, 2015). Mientras, en el seno de la CGT se conformó una corriente más combativa —el Movimiento de Trabajadores Argentinos (MTA) - que junto con la mencionada CTA protagonizaron algunos hechos de protestas mediante huelgas 
de alcance nacional como la desarrollada el 9 de noviembre de 1992 y luego acciones conjuntas como la "Marcha Federal" en julio de 1994 (Armelino, 2004).

Las primeras acciones, caracterizadas como estallidos o rebeliones, tuvieron epicentro en provincias como Santiago del Estero y Jujuy en las que las propias dinámicas de las conflictividades locales ingresaron en una nueva fase en el contexto instaurado por la administración de Carlos Menem. Acontecimientos como el Santiagazo en 1993 y el Jujeñazo en 1994 marcaron respuestas a la nueva situación socioeconómica que afectaron a las élites locales pero se mantuvieron relativamente aislados. El triunfo electoral de Carlos Menem en las elecciones de 1995 puede tomarse como una ratificación del rumbo y una muestra de las limitaciones de la protesta para producir cambios a escala nacional, aun en el marco del deterioro de las condiciones sociolaborales y de protestas obreras como la que en ese año le costó la vida a Víctor Choque en Tierra del Fuego.

Sin embargo, la crisis desatada como "efecto Tequila" alteró condiciones internacionales y tuvo un impacto en el funcionamiento del modelo económico. En 1996, con una desocupación en el 17,3\% y un 39\% de población en la pobreza (véase tabla 2) surgieron nuevas respuestas beligerantes, localizadas en provincias como Neuquén y Salta, que en contextos de puebladas, es decir, levantamientos localizados policlasistas y multisectorales (aunque con fuerte presencia de clase trabajadora) que forjaron un nuevo repertorio de acción: el piquete o corte de ruta ${ }^{[6]}$. Las consecuencias de la crisis económica y la aceleración del desempleo como problema central configuraron un escenario para la aparición de colectivos de desempleados que se nuclearon en organizaciones asentadas sobre experiencias sindicales, territoriales y comunitarias (algunas de ellas eclesiales). La expansión del desempleo en la segunda mitad de los años noventa generó un contexto de oportunidades que fue aprovechado por desocupados gracias a las tramas organizativas (que autores como Melucci identifican como laboratorios e incubadoras de acción colectiva), un repertorio de acción (el piquete) y el acceso a recursos que funcionaron como incentivos (programas de transferencias de ingresos condicionados y transitorios) en el marco de elementos propios de la cultura de la protesta, ligada tanto a la práctica sindical como a la comunitaria (Auyero, 2002).

La aparición de un sector de trabajadores que no podía ser representado por la CGT, en tanto no eran asalariados formales, y con dificultades para ser cobijados por la CTA que intentó representarlos mediante la afiliación directa y voluntaria, constituye el dato más significativo en el campo de la protesta del segundo lustro de los noventa. Sin embargo, esto no debe hacer perder la atención respecto a la conflictividad en el campo sindical en acciones defensivas (Iñigo Carreras y Cotarelo, 2003), ni tampoco en relación con otros campos de movilización como las luchas por los derechos humanos que, bajo la consigna de "verdad, memoria y justicia”, produjeron acciones colectivas que regeneraron el espacio público ${ }^{[7]}$.

Las condiciones de acción de los trabajadores organizados en sindicatos se vieron alteradas por la propia situación económica y la obturación de instituciones laborales que canalizaban la conflictividad en el ámbito laboral, como la anulación de las paritarias tripartitas. Las estrategias de las organizaciones sindicales, que Murillo llamó de subordinación y de supervivencia, funcionaron como diques de contención y desarticulación de la potencial conflictividad. Sin embargo, a partir de 1996 la beligerancia fue expresada por las centrales sindicales con huelgas generales como la del 8 de agosto y la del 26-27 de septiembre, ocasión en la que la CGT participó junto con el MTA y la CTA (Armelino, 2004).

La derrota del oficialismo en las elecciones de 1997 y los efectos incipientes de una recesión económica dinamizaron el conflicto en una fase de aceleración del ciclo de protestas que fue incorporando actores sindicales, jubilados y la consolidación del movimiento de trabajadores desocupados. En especial, los desocupados se arraigaron en sectores periféricos a los grandes conglomerados urbanos como Buenos Aires, Rosario, Córdoba y Mendoza, otrora cordones industriales de desigual desarrollo. El movimiento de trabajadores albergó a un conjunto heterogéneo de organizaciones con diferentes orientaciones ideológicas (autonomistas, guevaristas, maoístas, peronistas, troskistas) que enarbolaban la demanda de "trabajo". Este movimiento de movimientos se valió de la efectividad del piquete como repertorio de acción colectiva que 
le otorgó visibilidad y eficacia. Por su parte, en lo que concierne al movimiento obrero, la situación de 1997 muestra "la fractura y el creciente aislamiento, [que] hacen evidente que se ha entrado en un momento descendente del movimiento huelguístico. Al año siguiente no hubo huelgas generales" (Iñigo Carrera, 2001, p. 15), en un contexto en que el descontento parecía ser tramitado por la oposición política.

Los repertorios de acción colectiva, como muestran Schuster et al. (2006, también Schuster y Pereyra, 2001), evidenciaron una transformación en la década de los noventa. Especialmente, relevan la centralidad que adquirieron demandas y modos de acción en torno a demandas de matriz ciudadana y ampliación de derechos. Esto, en cierto modo, en detrimento de las acciones desplegadas por los actores clásicos, en particular los sindicatos en el periodo.

La asunción de la presidencia de Fernando De la Rúa, como resultado del triunfo de la Alianza Unión Cívica Radical (UCR)-Frente País Solidario (Frepaso) en las elecciones de 1999 prometía la continuidad del modelo económico, pero con erradicación de la corrupción ligada al gobierno de Carlos Menem. Esto es una evidencia de los límites en los alcances de la movilización social, que reclamaba un cambio de modelo hacia uno capaz de generar condiciones de respuesta a la principal demanda: el trabajo como vía de acceso a una ciudadanía social y política (Retamozo, 2009). No obstante, a poco de asumir, se pusieron en evidencia los límites del propio modelo de acumulación - tanto en su fase productiva como en la distributiva- y los indicadores sociales (pobreza y desocupación) continuaron mostrando el deterioro de las condiciones sociales (véase tabla 2). Los intentos por estabilizar variables macroeconómicas a partir de medidas acordadas con el Fondo Monetario Internacional (FMI) encontraron múltiples resistencias y escándalos de corrupción salpicaron al gobierno nacional y rompieron la coalición gobernante, lo cual terminó provocando la renuncia del vicepresidente Carlos Chacho Álvarez.

Ante el deterioro de la situación económica, se hicieron presentes en el ciclo de protesta con mayor fuerza y disrupción los movimientos de desocupados, movimientos estudiantiles, sindicatos del sector público enrolados en la CTA y los gremios nucleados en el MTA ${ }^{[8]}$. La situación de dislocación hegemónica tuvo un momento de evidencia en las elecciones legislativas del 2001, que marcaron un récord de votos en blanco, ausentismo e impugnados voluntarios y puede considerarse el síntoma de la crisis de representación política. A su vez, las variables macroeconómicas indicaban claros indicios de agotamiento intrínseco del modo de acumulación bajo la convertibilidad (Bonnet, 2007). Las medidas implementadas por el ministro Domingo Cavallo, quien había ocupado la cartera de Economía en el gobierno de Carlos Menem, orientadas a restringir el acceso a cajas de ahorro dolarizadas en los bancos, desataron una ola de descontento de sectores medios que terminó, junto con la acción de movimientos de desocupados y la oposición política, por poner en jaque al gobierno. Fernando de la Rúa renunció el 20 de diciembre del 2001, luego de actos represivos de la protesta social que dejaron alrededor de cuarenta muertos.

Las protestas de diciembre del 2001 aglutinaron a un conjunto heterogéneo de sectores con diversas demandas, fundamentalmente sectores medios alcanzados por la crisis social que se manifestaban mediante "cacerolazos", los sectores desempleados que venían de experiencias de articulación a escala nacional y trabajadores formales, sobre todo del sector público, a los que se les había reducido un $13 \%$ el salario para enfrentar el déficit fiscal. En esos espacios de encuentros, la protesta cobró potencia y forma bajo consignas como “Que se vayan todos!”, o “iPiquete y Cacerola, la lucha es una sola!”. El saldo organizativo de esas movilizaciones lo constituyeron las asambleas barriales o populares que funcionaron en los grandes centros urbanos como lugar de encuentro de sectores medios por fuera de las estructuras de participación de la democracia representativa (Falleti, 2008).

Luego de días de inestabilidad institucional por la renuncia de varios presidentes, Eduardo Duhalde asumió la presidencia y tomó la decisión de poner fin a la convertibilidad, que estipulaba la paridad por ley entre el peso argentino y el dólar estadounidense. El triunfo del sectores que proponían la salida de la convertibilidad vía la devaluación (frente los que proponían la dolarización directa de la economía), en el que participaban sectores sindicales, produjo un realineamiento de las élites gobernantes. Duhalde promovió la pesificación 
de deudas contraídas en dólares, lo que benefició a grupos empresariales, e implementó un programa de transferencia de ingresos condicionada, el Plan Jefes y Jefas de Hogar Desocupados, que llegó a beneficiar a casi 2.000.000 de personas a mediados del año 2003 y significó el acceso a un ingreso a los hogares más pobres. Además, los recursos destinados a este programa llegaron a representar casi el $1 \%$ del Producto Bruto Interno (PBI), porcentaje que no se había registrado y monto muy superior a lo históricamente destinado a las políticas de empleo (Neffa, 2008). La medición de mayo del 2002 arrojó los peores indicadores históricos en materia social, con un $62 \%$ de pobreza y $17,8 \%$ de desocupación (véase tabla 2 ).

Un informe del Ministerio de Justicia, titulado "Conflictividad social en la República Argentina” y publicado en junio de 2002 por el diario Clarín, estima que en el periodo enero-mayo del 2002 en la zona metropolitana se produjeron 11.000 acciones de protesta donde participaron unas 650.000 personas. El 26 de junio de ese año, en una protesta en un acceso a la Capital Federal fueron asesinados dos jóvenes manifestantes (Maximiliano Kosteki y Darío Santillán), lo que generó movilizaciones multisectoriales y el llamado a elecciones presidenciales para comienzos del año siguiente. Hacia finales del 2002, algunas variables macroeconómicas detuvieron su caída y el resultado de las elecciones del 2003 —en cuanto asistenciafue un signo de confianza en cierta institucionalidad democrática, aunque no en referencia a los políticos profesionales.

\section{La década K: recomposición, alcances y límites}

La asunción de Néstor Kirchner el 25 de mayo del 2003 marca la apertura de un nuevo ciclo político y la consolidación de un nuevo régimen social de acumulación, especialmente partir del 2005 (Panigo y Chena, 2011) y la reposición de la matriz estatal-nacional-popular ${ }^{[9]}$. En el plano político, la construcción del incipiente "kirchnerismo" articuló alianzas con diferentes sectores políticos, a través de la llamada "transversalidad" (Torre, 2005), un vínculo con los movimientos sociales (Andriotti Romanin, 2014; Schuttenberg, 2011) y con la Confederación General del Trabajo (Funes, 2016; Murillo, 2013). La alianza con la central obrera terminó por consolidarse cuando Néstor Kirchner apoyó la candidatura al secretariado general del camionero Hugo Moyano en el 2005. En ese momento, el presidente Kirchner obtenía el 71\% de aprobación, según los datos del Latinobarómetro. La salida del ministro de Economía fue la conclusión de una tensión sobre la performatividad de la política a la hora de revitalizar gramáticas de resolución de conflictos. Lavagna buscaba poner un límite al funcionamiento de la institucionalidad laboral que regula la negociación colectiva, para evitar aumentos de salarios por fuera de una pauta específica y que esto impacte en la inflación. La CGT enfrentó esta situación y el presidente Néstor Kirchner inclinó la balanza a favor de la central obrera para liberar la negociación colectiva al alza (Palomino y Trajtemberg, 2006). La expansión de la economía y la creación de puestos de empleo formales durante el gobierno de Néstor Kirchner produjeron una reactivación de los sindicatos como actores protagónicos del conflicto (Barattini, 2013). 


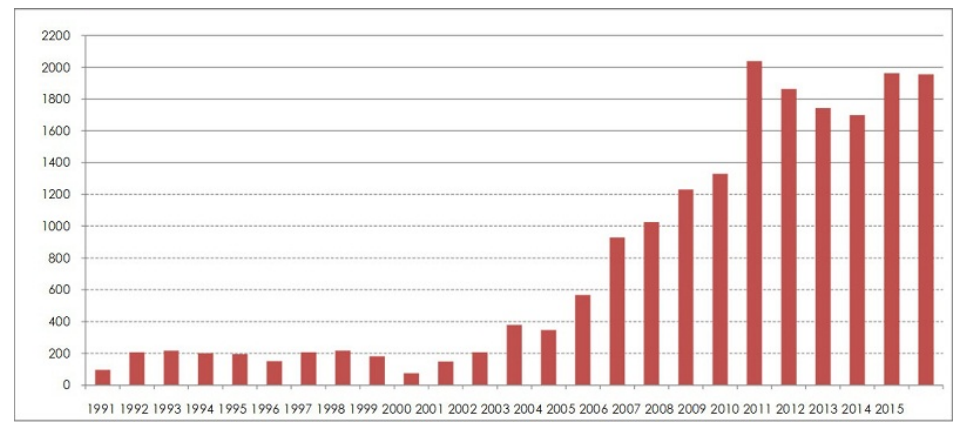

FIGURA 1

Número de convenios y acuerdos homologados (1991-2015)

Nota: desde el primer trimestre del 2010 se emplea como definición operativa el criterio de "registro de acuerdos y convenios en la Dirección Nacional de Relaciones de Trabajo (DNRT)”, principalmente para reflejar aquellas negociaciones que en determinadas actividades, ramas y empresas tienden a ser recopiladas en una misma resolución homologatoria. Ahora un registro de la DNRT equivale a un acuerdo o convenio colectivo.

Fuente: elaboración propia con base en datos de la Subsecretaría de Programación

Técnica y Estudios Laborales. Ministerio de Trabajo, Empleo y Seguridad Social

Como puede apreciarse en la figura 1, fue muy importante el aumento de convenios y acuerdos firmados en instancias tripartitas, cuyos efectos sobre la distribución del ingresos han sido puestos en evidencia (Casanova y Alejo, 2015; Judzik, Trujillo y Villafañe, 2017; Trajtemberg, 2009, 2011). Esto recondujo la dinámica del conflicto y una polémica sobre el tipo de "revitalización sindical" ocurrido en el país (Anigstein, 2013). En particular, porque si bien existe evidencia suficiente para afirmar la revigorización del accionar de los sindicatos, no tuvo lugar una creación masiva de nuevas prácticas gremiales o formas de representación (Senén González y Haidar, 2009), aunque hubo experiencias significativas ligadas al sindicalismo de base (Lenguita, 2011). Para algunos autores, el proceso puede caracterizarse como la configuración de un neocorporativismo segmentado (Etchemendy y Collier, 2008). La relativa institucionalización del conflicto durante el gobierno de Néstor Kirchner fue compatible con un incremento de la acción extrainstitucional por parte de diferentes colectivos. Sin embargo, a diferencia del ciclo anterior, las movilizaciones incluyeron tanto acciones con reivindicaciones críticas al gobierno como acciones y movilizaciones en su apoyo, incluso fuera de actos proselitistas, cosa que no ocurría, al menos desde que en 1990 sectores ligados al presidente Menem convocaron a la llamada "Plaza del Sí".

En esta misma fase aparecieron y se robustecieron demandas ligadas a problemáticas socioambientales tanto por la instalación de pasteras trasnacionales como por minería a cielo abierto y procesos de expansión del cultivo de soja (Svampa y Viale, 2015). También cobraron protagonismo y visibilidad en la escena pública las movilizaciones en torno al problema de (in)seguridad (Schillagi, 2006). Estas acciones resignificaron repertorios de acción colectiva como la realización de asambleas, cortes de rutas y marchas del silencio cuyo valor había sido probado para instalar temas en la arena pública (Schuster et al., 2006). En este sentido, no se trataba solo de la implementación de repertorios forjados en el ciclo anterior, sino de una gramática de movilización reposicionada (Cefaï, 2002).

El gobierno nacional buscó dar respuestas a estas demandas, a través de diferentes estrategias como la canalización institucional, la representación simbólica y el desconocimiento. Durante la gestión de Néstor Kirchner se incorporaron al gobierno nacional dirigentes de movimientos sociales que habían protagonizado la protesta durante los años noventa (Bazán, 2012), aunque otros se mantuvieron en campo opositor y motorizaron acciones contenciosas ${ }^{[10]}$.

El 10 de diciembre del 2007 asumió la presidencia Cristina Fernández de Kirchner, luego de obtener el 45,3\% de los votos. Lo que parecía una continuidad de la gestión se vio marcado por un cambio de fase cuando a partir de la Resolución 125/08 del Ministerio de Economía se desencadenó una ola de protestas liderada por entidades empresarias del sector agrario. Este conflicto, que duró entre marzo y julio de ese año, evidenció el uso de repertorios de acción forjados al calor de las protestas contra el neoliberalismo, pero instrumentados 
por sectores que reclamaban preservar la rentabilidad de las exportaciones, tales como el corte de ruta o "piquetes" y la realización de asambleas. Según la consultora Nueva Mayoría (2008),

de acuerdo al estudio, entre el $1^{\circ}$ de enero y el 18 de mayo del 2008 tuvieron lugar 2.539 cortes de rutas y vías públicas como expresión de protesta, cifra que supera el nivel de cortes registrados en la crisis política, económica y social del 2001/2002 con 1.383 y 2.336 cortes respectivamente, siendo a su vez la tendencia más alta registrada desde que se lleva este indicador de conflictividad social en el $1^{\circ}$ de enero de 1997. (s. p.)

Sin embargo, cabe notar que la movilización afirmativa - es decir, de apoyo al gobierno- también se incrementó en esta fase del ciclo. Según los datos de Nueva Mayoría, durante todo el 2008 se registraron “5.608 cortes de rutas y vías públicas como expresión de protesta”. De estas acciones, solo el $1 \%$ fueron protagonizadas por organizaciones de desocupados y el $4 \%$ por organizaciones sindicales, mientras que el $70 \%$ estuvo a cargo de entidades ligadas a los agronegocios ${ }^{[11]}$.

El conflicto del 2008, la disputa por el excedente, por las necesidades del modelo económico y un contexto marcado por la crisis mundial de ese año tuvieron efectos sobre la correlación de fuerzas en escena. En ese contexto aparecieron acciones colectivas de sectores de clase media urbana bajo el formato de "cacerolazos" (Garguín, 2013) y la primera derrota del partido gobernante en las elecciones legislativas del 2009 (Piana y Baeza, 2013). Sin embargo, el gobierno recuperó la iniciativa política con una agenda que incluyó la absorción de demandas de movimientos sociales históricos - como los LGTTB (Biglieri, 2013) y la Coalición para una Radiodifusión (Marino, Mastrini y Becerra, 2010). El campo de movilización evidencia, especialmente en esta fase, acciones afirmativas convocadas a posteriori de decisiones del gobierno, participación en espacios institucionales (ejecutivos y parlamentarios) y acciones de protesta de colectivos opositores.

A lo largo del 2010 sucedieron dos eventos de movilización masiva cuya importancia es insoslayable para el periodo y que no entran en los formatos clásicos de acción colectiva. El primero, en torno a los festejos del Bicentenario, en el que una serie de actividades convocadas por el gobierno generaron la participación de millones de personas bajo una cosmovisión "nacional y popular" de la efemérides (González, 2015). La otra, el 27 de octubre del 2010, a partir de la repentina muerte del expresidente Néstor Kirchner que desencadenó un proceso de movilización en torno a su velatorio en la Casa de Gobierno y alrededor de su figura como espacio de inscripción identitaria (Souroujon, 2016).

Entre los nuevos actores de la fase se destaca la condición del accionar juvenil qua joven. En efecto, aunque muchos de los participantes de acciones de protestas (incluso en el ciclo 1989-2003) eran jóvenes, su participación no estaba enfocada en el carácter etario de la organización. Sin embargo, en esta fase hacia el 2010 - se registra un nivel de organización juvenil plasmado en organizaciones como la Cámpora (promovida por el kirchnerismo), la JP Evita (rama juvenil del Movimiento Evita) y la Juventud Sindical Peronista (impulsada por sectores del movimiento obrero) ${ }^{[12]}$.

La salida del estancamiento y de la crisis financiera internacional generó condiciones económicas que ayudan a comprender el resposicionamiento del kirchnerismo en el centro de la escena política. Luego de un decrecimiento del PBI en el 2009, se pasó a un incremento superior al 9\% en el 2010, el desempleo se redujo en un punto y la formalidad laboral alcanzó su punto más alto ${ }^{[13]}$. 
TABLA 3

PBI, inflación, pobreza, desempleo, formalidad y desigualdad 2003-2015

\begin{tabular}{|c|c|c|c|c|c|c|}
\hline Ańo & PBI $(*)$ & Inflación $(* *)$ & Pobreza $\left({ }^{* * *}\right)$ & Desempleo $\left.{ }^{* * * *}\right)$ & Formalidad $\left({ }^{* * * * *}\right)$ & Gini $\left({ }^{* * * * * *}\right)$ \\
\hline 2003 & 8,8 & 7,3 & 58,5 & 14,4 & 56,80 & 0,54 \\
\hline 2004 & 9,0 & 4,9 & 52,8 & 12,0 & 55,99 & 0,49 \\
\hline 2005 & 9,2 & 9,6 & 46,6 & 10,0 & 57,89 & 0,48 \\
\hline 2006 & 8,5 & 10,6 & 40,6 & 8,6 & 59,70 & 0,48 \\
\hline 2007 & 8,2 & 17,6 & 37,8 & 7,5 & 62,21 & 0,46 \\
\hline 2008 & 4,4 & 25,1 & 36,1 & 7,3 & 63,53 & 0,45 \\
\hline 2009 & $-3,4$ & 14,1 & 33,5 & 8,4 & 64,78 & 0,45 \\
\hline 2010 & 9,3 & 26,9 & 32,1 & 7,3 & 67,05 & 0,44 \\
\hline 2011 & 6,5 & 24,5 & 28,0 & 6,7 & 66,74 & 0,44 \\
\hline 2012 & $-0,5$ & 25,7 & 27,9 & 6,9 & 66,24 & 0,41 \\
\hline 2013 & 2,4 & 20,5 & 27,5 & 6,4 & 67,29 & 0,41 \\
\hline 2014 & $-2,5$ & 37,9 & 32,7 & 6,9 & 66,73 & 0,42 \\
\hline 2015 & 2,6 & 27,3 & 30,5 & 6,5 & $s / d$ & $\mathrm{~s} / \mathrm{d}$ \\
\hline
\end{tabular}

Fuente: Cavallo y Bertolotto (2016) y Gasparini y Tornarolli (2017)

* Tasa de cambio anual con base en el proyecto ARKLEMS+LAND. Años 2013-2015 con base en datos de la Cepal.

** Inflación verdadera, tasa de inflación anual al mes de julio.

*** Datos comparables con base en la nueva metodología oficial de

cálculo de la pobreza aplicada a partir del año 2016 por el INDEC.

**** EPH-INDEC, Ministerio de Trabajo Empleo y Seguridad Social, datos del trimestre IV de cada año.

${ }^{* * * * *}$ EPH-INDEC. Porcentaje de asalariados registrados respecto del total del empleo asalariado. Los asalariados que declaran tener descuento jubilatorio se asumen como registrados. Datos del trimestre IV de cada año. ${ }^{* * * * * *}$ Cálculos propios con base en la EPH-continua-segundos semestres, INDEC, IPCF.

A esto hay que sumarle la concurrencia de variables del contexto político, como una oposición fragmentada que facilitó la obtención de más del 54\% de los votos para la reelección de Cristina Fernández de Kirchner. Paradójicamente, la convergencia de un triunfo abultado (la dimensión política) y la situación económica contribuyó a "realineamientos", que Tilly (1998) define como "la lucha, la defensa y la cooptación alteran las alianzas, rivalidades y enemistades entre gobernantes, otros contendientes y los grupos reivindicativos" ( $p$. 36).

A partir del 2012, se abre una nueva fase del ciclo político. Los sectores que participan de la economía informal avanzaron su organización en torno a cooperativas impulsadas en el Programa Ingreso Social con Trabajo-Argentina Trabaja, creado en 2009, mientras que los sectores asalariados formales, especialmente los enrolados en la CGT, comenzaron a presionar con demandas sectoriales que cobraron fuerza a partir de la 
ruptura de la alianza entre el gobierno nacional y varios sindicatos. En esta fase del ciclo, el funcionamiento de las instituciones laborales como canales de resolución del conflicto social no agotó la conflictividad y esta se expandió al llamado de huelgas generales o movilizaciones de alcance nacional ${ }^{[14]}$. Es decir, las respuestas a la nueva situación fueron el incremento de la conflictividad sindical entre los trabajadores formalizados y un conjunto de acciones colectivas por parte de los sectores que gestionaban programas de cooperativas como el Argentina Trabaja. Sin embargo, el espacio de acción de las organizaciones populares que intermediaban en la implementación de programas sociales se vio reducido por la implementación de la asignación universal por hijo que desde finales del 2009 promovía una transferencia monetaria condicionada a los hijos de los trabajadores desempleados o no registrados, mediante transferencia bancaria directa a la madre o padre del menor. Esta política se instaló como superadora del plan Jefes y Jefas de Hogar Desocupados y del Plan Familias. Aun en este contexto desfavorable para la acción colectiva, bajo la consigna de "cooperativas sin punteros", un conjunto de organizaciones se nucleó en torno a la demanda de ampliación y aumento de los montos percibidos en el marco de la política pública, tanto del programa de cooperativas Argentina Trabaja como del Ellas Hacen (Nardin, 2017; Natalucci, 2012). Asimismo, emergieron acciones de protestas vinculadas al problema habitacional y de urbanización de "villas" en la ciudad de Buenos Aires que asumieron un formato de "acampe" (L'Huillier y Ouviña, 2016).

Al tiempo que sucedían estas protestas, sobre todo durante el 2012, emergieron acciones de alcance nacional con una impronta cívica (con el eje puesto en la corrupción) y económica (con la demanda de libre acceso a la compra de dólares). Los llamados "cacerolazos" del 13-S y del 8-N y del 13-A en el 2013 (Gold, 2015; Gómez, 2014) que instalaron una potencia opositora sin una representación política, pero aprovechando la expansión de la estructura de oportunidades políticas (Tilly, 1998, p. 38). La pérdida de aliados del gobierno (sectores políticos y sindicales), el incremento de la protesta de los sectores medios y un contexto de cierre de fuentes de financiamiento internacional y déficit de divisas en lo económico fueron condiciones involucradas en la derrota electoral del gobierno nacional en el principal distrito, a manos del otrora aliado Sergio Massa (Annunziata, 2015; Tagina, 2014).

La dinámica de movilización de las organizaciones que apoyaron al gobierno adquirió cada vez más una impronta delegativa y laudatoria como respaldo a la gestión (cuya muestra más significativa fueron los "patios militantes”, donde el activismo kirchnerista se congregaba para escuchar los discursos de Cristina Fernández de Kirchner). Mientras, en el campo opositor se sucedían medidas de fuerza de importantes sectores sindicales que reclamaban cambios en el impuesto a las ganancias (Murillo, 2013) y manifestaciones de sectores mediosaltos mediante "cacerolazos" y un creciente activismo en las redes sociales (Ingrassia, 2016).

Hacia el final del periodo, luego de una muy fuerte reducción del desempleo y creación de puestos en el mercado formal, se evidenció un periodo de estancamiento en la creación de nuevos empleos y la persistencia de un importante sector de la clase trabajadores en condiciones informales, precarias, no registradas legalmente, o bajo formas de cuenta propia de baja calificación e ingresos. Además de otra cantidad de trabajadores que desempeñaban actividades laborales y de capacitación en el marco de los programas sociales (Abal Medina, 2016). Hacia el 2011 comenzaron a aglutinarse organizaciones sociales ligadas al problema del empleo informal que definieron a lo que llamaron "economía popular" como un espacio constitutivo de experiencias de clase. Así nació la Confederación de Trabajadores de la Economía Popular (CTEP) (Tóffoli, 2017). La CTEP combina lógicas de organización sindical (con agremiaciones por rama de la economía tal como la CGT) con formas de acción colectiva propias del movimiento social argentino (acampes, cortes de ruta, ollas populares) y se ha convertido en el actor más novedoso emergido en la última fase del ciclo político del kirchnerismo en el gobierno, cuyo protagonismo cobró impulso luego de la asunción de Mauricio Macri de la presidencia de la Nación el 10 de diciembre del 2015. 


\section{Conclusiones}

El estudio de los procesos políticos requiere la ruptura de visiones dicotómicas que culminan por concebir la acción como mera reacción a transformaciones estructurales o por desanclar a los actores de sus determinaciones (entendidas como limitantes y habilitantes). Esto reposiciona las mediaciones sociales, organizacionales, culturales y metodológicas que ayudan a explicar la consecución de acciones colectivas, ya sea de protesta, pero también las afirmativas propias de una sociedad en movimiento. Este artículo puso en evidencia la dinámica de los dos ciclos políticos analizados y sus diferentes fases. La articulación entre reconstruir los aspectos estructurales que constituyen condiciones para las prácticas de movilización política, los repertorios de acción y las respuestas gubernamentales constituyen un enfoque relacional productivo para el estudio del proceso político.

El ciclo 1989-2002 muestra distintas fases. Las reformas neoliberales implementadas a poco de asumir por Carlos Menem fueron enfrentadas fragmentariamente por organizaciones sindicales afectadas de manera directa por las privatizaciones y la reforma del Estado tendiente a su descentralización y achicamiento. El conflicto, escenificado con repertorios clásicos como la huelga y la movilización, tuvo una tónica defensiva y con escasos resultados para los manifestantes. Sin embargo, produjo saldos organizativos como la conformación de la CTA y el MTA.

En una segunda fase se evidencia con movilizaciones policlasistas contra las élites provinciales en el marco de los primeros efectos visibles del nuevo régimen social de acumulación. Las puebladas en Santiago del Estero y en Jujuy fueron muestra de ello. Allí mostraron sinergia lógicas gremiales contestatarias con formas de acción directa como la quema de edificios públicos. Luego de la reelección de Carlos Menem se inicia una fase ascendente del ciclo de protestas con las "puebladas" en provincias como Neuquén y Salta. Esta fase muestra la persistencia del bagaje de repertorios de acción sindical en disponibilidad, experiencias y la aparición del corte de rutas como una forma sistemática de escenificar la protesta. La persistencia de los "piquetes" fue un rasgo central de las movilizaciones que demandaron en torno al núcleo de la nueva cuestión social: la falta de trabajo. No es casualidad que la prensa diera a conocer como "piqueteros" a los movimientos de trabajadores desocupados, ni que su acción se viera incrementada hasta el 2002.

Por su parte, a partir del 2003, se abre un nuevo ciclo con intensas movilizaciones. La repolitización social involucró a fuerzas movilizadas en torno al proyecto gubernamental en la medida que, por un lado, cambiaba la situación socioeconómica, y por otro, el gobierno interpelaba a colectivos movilizados atendiendo a sus demandas. La recomposición de mediaciones societatales, como las instituciones laborales, repusieron a los sindicatos como actores sociopolíticos aunque las organizaciones de desocupados, ahora centradas en gestionar programas sociales, también fueron parte de la acción. Cabe destacar que luego de una fase de recomposición, a partir del primer mandato de Cristina Fernández de Kirchner, se da lugar a un nuevo periodo marcado por el conflicto entre las entidades empresariales ligadas a los agronegocios y el gobierno nacional. Paradójicamente, sectores conservadores repusieron en la escena pública una serie de repertorios forjados al calor de la resistencia al neoliberalismo en los años noventa como el piquete, las asambleas y los cacerolazos. La conflictividad encontró actores enfrentados con repertorios de protesta y de movilización afirmativa, tanto provenientes de lógicas de movimiento social como de iniciativas gubernamentales. La recuperación económica hacia el 2010, luego de la crisis internacional, otorgó capital al gobierno nacional para promover acciones colectivas e iniciativas institucionales (mediante leyes), de manera articulada. No obstante, luego del triunfo de Cristina Fernández de Kirchner, en el contexto de un amesetamiento económico y ruptura de alianzas, el campo opositor concitó movilizaciones desde sectores asalariados formales y también sectores medios altos descontentos con el rumbo económico del gobierno. La acción sindical, mediante huelgas, y los cacerolazos diversificaron los repertorios de oposición, que fueron canalizados electoralmente por Sergio Massa en el 2013 y finalmente por Mauricio Macri en el 2015. 
A lo largo de este trabajo pudimos mostrar la necesidad de incluir las dimensiones estructurales, así como las dinámicas propias de los agentes y los campos de la movilización. En este sentido, el artículo buscó aportar tanto a la comprensión de las formas de movilización en los diferentes ciclos políticos en Argentina como consolidar un enfoque en el estudio de los procesos políticos de disputa por el orden social.

\section{Referencias}

Abal Medina, P. (2016). Los trabajadores y sus organizaciones durante los gobiernos kirchneristas. Nueva Sociedad, (264), 72-86. Recuperado de https://www.nuso.org/media/articles/downloads/4._TC_Abal_Medina_264.pd $\mathrm{f}$

Altimir, O., Beccaria, L., y González Rozada, M. (2002). La distribución del ingreso en Argentina. 1974-200. Revista Cepal, (78), 55-85. Recuperado de https://www.cepal.org/es/publicaciones/10851-la-distribucion-ingreso-arg entina-1974-2000

Andriotti Romanin, E. (2014). ¿Cooptación, oportunidades políticas y sentimientos?: las Madres de Plaza de Mayo y el gobierno de Néstor Kirchner. Polis (Santiago), 13(39), 229-247. DOI: https://doi.org/10.4067/S0718-656 82014000300011

Anigstein, C. (2013). ¿Combatividad encauzada o recomposición del trabajo organizado? La dinámica de la negociación colectiva en los gobiernos kirchneristas . Amérique Latine Histoire et Mémoire. Les Cahiers ALHIM, 26. Recuperado el 15 de enero del 2019, de https://www.journals.openedition.org/alhim/4757

Annunziata, R. (2015). Liderazgos de proximidad y procesos electorales: los casos de Sergio Massa y Martín Insaurralde en las legislativas de 2013. En R. Annunziata (comp.), Pensar las elecciones. Democracia, líderes y ciudadanos (pp. 95-128). Buenos Aires: Clacso.

Arakaki, A. (2011). La pobreza en Argentina 1974-2006. Construcción y análisis de la información. Buenos Aires: Centro de Estudios sobre Población Empleo y Desarrollo, documento de trabajo n. ${ }^{\circ} 15$.

Armelino, M. (2004). Algunos aspectos de la acción colectiva y la protesta en la CTA y el MTA. Laboratorio, 15, 5-12. Recuperado de https://www.biblioteca.clacso.edu.ar/Argentina/iigg-uba/20120621065252/lavbo15.pdf

Armelino, M. (2012). Kind of blue. Las vicisitudes de la Central de Trabajadores Argentinos (CTA) durante los años kirchneristas. En G. Pérez y A. Natalucci (eds.), Vamos las bandas. Organizaciones y militancia kirchnerista (pp. 101-126). Buenos Aires: Nueva Trilce.

Aronskind, R., y Vommaro, G. (2010). Campos de batalla. Las rutas, los medios y las plazas en el nuevo conlicto agrario. Buenos Aires: UNGS-Prometeo.

Auyero, J. (2002). Los cambios en el repertorio de la protesta social en la Argentina. Desarrollo Económico, 42(166), 187-210. Recuperado de https://www.jstor.org/stable/3455940

Barattini, M. (2013). La vitalización sindical en el período de la convertibilidad en Argentina. Trabajo y Sociedad, (20), 193-203. Recuperado de https://www.unse.edu.ar/trabajoysociedad/20\%20BARATTINI\%20convertibilidad \%20sindicatos.pdf

Bazán, C. B. (2012). El aluvión: del piquete al gobierno: los movimientos sociales y el kirchnerismo. Buenos Aires: Sudamericana.

Biglieri, P. (2013). Emancipaciones. Acerca de la aprobación de la ley del matrimonio igualitario en Argentina. Íconos. Revista de Ciencias Sociales, (46). DOI: https://doi.org/10.17141/iconos.46.2013.97

Bonnet, A. (2007). La hegemonía menemista: el neoconservadurismo en Argentina, 1989-2001. Buenos Aires: Prometeo Libros Editorial.

Casanova, L., y Alejo, J. (2015). El efecto de la negociación colectiva sobre la distribución de los ingresos laborales. Evidencia empírica para Argentina en los años dos mil. Buenos Aires: OIT, documento de trabajo n. ${ }^{\circ} 8$.

Cavallo, A., y Bertolotto, M. (2016) Serie completa de inflación Argentina de 1943 a 2016. Recuperado de https://w ww.mit.edu/ afc/papers/FillingTheGap_es.pdf 
Cefaï, D. (2002). ¿Qué es una arena pública? Algunas pautas para un acercamiento pragmático. En D. Cefaï y e I. Joseph (coords.), La herencia del pragmatismo. Conflictos de urbanidad y pruebas de civismo (pp. 51-81). La Tour d'Aigues: Éditions de l'Aube.

Cotarelo, C. e Iñigo Carrera, N. (2016). Las huelgas generales después de la crisis. Argentina 2002-2014. En III International Conference Strikes and Social Conflicts: combined historical approaches to conflict. Proceedings, 2016 (pp. 83-96).

Di Tella, T. S. (1998). El futuro de los partidos políticos en la Argentina. Revista de la Cepal, 343-350. Recuperado de https://www.cepal.org/es/publicaciones/37962-revista-la-cepal-nro-extraordinario-cepal-cincuenta-anos

Etchemendy, S., y Collier, R. (2008). Golpeados pero de pie: resurgimiento sindical y neocorporativismo segmentado en Argentina (2003-2007). Postdata, (13), 145-192.

Falleti, V. F. (2008). Reflexión teórica sobre el proceso sociopolítico y la subpolítica. Un estudio de caso: el "cacerolazo" y las asambleas barriales. Revista Mexicana de Sociología, 70(2), 361-398. Recuperado de https://www.scielo.o rg.mx/scielo.php?script=sci_arttext\&pid=S0188-25032008000200005\&lng=pt\&nrm=iso\&tlng=es

Funes, A. N. (2016). En el comienzo de todo...: Los orígenes constitutivos de la identidad kirchnerista durante el gobierno de Néstor Kirchner (2003-2007). Temas y Debates, (32), 51-74. Recuperado de https://www.scielo.o rg.ar/scielo.php?script $=$ sci_arttext\&pid=S1853-984X2016000200003

Garguín, E. (2013). La clase media en el discurso público. Cuestiones de Sociología, (9), 257-261. Recuperado de htt ps://www.memoria.fahce.unlp.edu.ar/art_revistas/pr.5888/pr.5888.pdf

Garretón, M. A., Cavarozzi, M., Cleaves, P, Gereffi, G., y Hartlyn, J. (2004). América Latina en el siglo XXI. Hacia una nueva matriz sociopolítica. Santiago de Chile: LOM Ediciones.

Gasparini L. (1999). Desigualdad en la distribución del ingreso y bienestar. Estimaciones para la Argentina. En Fundación de Investigaciones Económicas Latinoamericanas (FIELD), La distribución del ingreso en Argentina (pp. 35-85). Buenos Aires: Editorial FIEL.

Gasparini, L., y Tornarolli, L. (2017). La pobreza en Argentina. Recuperando la comparabilidad. Foco Económico. Recuperado de https://www.cedlas.econo.unlp.edu.ar/wp/wp-content/uploads/Informe-breve-Marzo-2017.p df

Giddens, A. (1984). The constitution of society. Cambridge, Reino Unido: Polity Press

Gold, T. (2015). Cacerolazos y legitimidad política en la Argentina reciente del "13- S" al "8-A". En R. Annunziata (comp.), Pensar las elecciones. Democracia, líderes y ciudadanos (pp. 183-210). Buenos Aires: Clacso, Instituto de Investigaciones Gino Germani, UBA

Gómez, M. (2014). Radiografía de los movilizados contra el kirchnerismo. Resultados de una encuesta a la concurrencia del 8N. Sudamérica: Revista de Ciencias Sociales, (3), 75-100. Recuperado de https://www.fh.mdp.edu.ar/rev istas/index.php/sudamerica/article/view/1052/1084

González, M. (2015). Configurar el relato: estética y montaje de imágenes performáticas en los festejos del bicentenario nacional. Anales del Instituto de Arte Americano e Investigaciones Estéticas. Mario J. Buschiazzo, 45(2), 119-132. Recuperado de https://www.scielo.org.ar/pdf/anales/v45n2/v45n2a03.pdf

Gordillo, M. B. (2004). Reforma del Estado y acciones colectivas: la huelga ferroviaria de 1991. Entrepasados, 13(26), 85-104.

Ingrassia, P. (2016). $8 \mathrm{~N}$ y $18 \mathrm{~F}$ en Clarín y Página 12. Estudio sobre la construcción informativa de dos marchas de alcance nacional. Question, 1(51), 406-424. Recuperado de https://www.sedici.unlp.edu.ar/handle/10915/56 188

Iñigo Carreras, N. (2001). Las huelgas generales, Argentina 1983-2001: un ejercicio de periodización. Buenos Aires: PIMSA, documento de trabajo 33.

Iñigo Carreras, N., y Cotarelo, M. C. (2003). La insurrección espontánea. Argentina diciembre 2001. Buenos Aires: Programa de Investigación sobre el Movimiento de la Sociedad Argentina (Pimsa), documentos y comunicaciones. 
Jelin, E. (1995). La política de la memoria: el Movimiento de Derechos Humanos y la construcción democrática en la Argentina. En C. Acuña et al., Juicio, castigos y memoria. Derechos humanos y justicia en la política argentina (pp. 101-146). Buenos Aires: Nueva Visión.

Judzik, D., Trujillo, L., y Villafañe, S. (2017). A tale of two decades: Income inequality and public policy in Argentina (1996-2014). Cuadernos de Economía, 36(72), 233-264. DOI: https://dx.doi.org/10.15446/cuad.econ.v36n7 2.65871

Larrondo, M. (2013). El discurso político kirchnerista hacia la juventud en contextos de actos de militancia. Astrolabio, (11), 334-363. Recuperado de https://www.revistas.unc.edu.ar/index.php/astrolabio/article/view/2891

Lenguita, P. (2011). Revitalización desde las bases del sindicalismo argentino. Nueva Sociedad, 232, 137-149. Recuperado de https://www.nuso.org/upload/articulos/3767_1.pdf

Levitsky, S. (2005). La transformación del justicialismo. Del partido sindical al partido clientelista. 1983-1999. Buenos Aires: Siglo XXI.

L'Huillier, F., y Ouviña, H. (2016). Del Indoamericano a la Carpa Villera. Derecho a la ciudad y luchas por la urbanización de las villas (2010-2016). Quid 16. Revista del Área de Estudios Urbanos, (6), 54-87. Recuperado de https://www.publicaciones.sociales.uba.ar/index.php/quid16/article/viewFile/2082/1771

Marino, S., Mastrini, G., y Becerra, M. (2010). El proceso de regulación democrática de la comunicación en Argentina. Oficios Terrestres, (25), 11-24. Recuperado de http://www.sedici.unlp.edu.ar/handle/10915/45366

Martuccelli, D., y Svampa, M. (1997). La plaza vacía: Las transformaciones del peronismo. Buenos Aires: Losada.

McAdam, D., Tarrow, S., y Tilly C. (2001). Dynamics of contention. Nueva York: Cambridge University Press.

Morris, M. B (2018). ¿El Movimiento obrero organizado? La acción política de las centrales sindicales argentinas (2007-2015) (tesis de doctorado en Ciencias Sociales). UNLP, La Plata, Argentina.

Murillo, M. V. (1997). La adaptación del sindicalismo argentino a las reformas de mercado en la primera presidencia de Menem. Desarrollo Económico, 37(147), 419-446. DOI: https://doi.org/10.2307/3467188

Murillo, M. V. (2013). Cambio y continuidad del sindicalismo en democracia. Revista SAAP, 7(2), 339-348. Recuperado de https://www.scielo.org.ar/pdf/rsaap/v7n2/v7n2a12.pdf

Mustapic, A. M. (2002). Del Partido Peronista al Partido Justicialista. Las transformaciones de un partido carismático. En M. Cavarozzi y J. M. Abal Medina (comps.)., El asedio a la política. Los partidos latinoamericanos en la era neoliberal (pp. 137-162). Rosario: Homo-Sapiens.

Nardin, S. (2017). Como echarle agua al mar: alteridad y distinción en la construcción identitaria de un movimiento de trabajadores desocupados. Trabajo y Sociedad, (29), 537-553. Recuperado de https://www.scielo.org.ar/scie lo.php?script $=$ sci_abstract\&pid $=$ S1514-68712017000200027

Natalucci, A. (2012). Políticas sociales y disputas territoriales: El caso del programa "Argentina Trabaja". Revista Perspectivas de Políticas Públicas, (3), 126-147. Recuperado de https://www.revistas.unla.edu.ar/perspectivas/ article/view/614

Natalucci, A y Galimberti, C. (2015). Juventud(es) sindical(es): identidades políticas y lógicas de acción. Socio Debate, 1(2), 98-130. Recuperado de https://www.feej.org/sociodebate

Natalucci, A., y Schuttenberg, M. (2010). Pensar el kirchnerismo: un estado del arte de los estudios sobre movimentismo e identidades nacional-populares. Peronismos, izquierdas y organizaciones populares. Movimientos e identidades políticas en la Argentina contemporánea (pp. 8-26). La Plata: EDULP.

Neffa, J. (2008). El Plan Jefes y Jefas de Hogar Desocupados: antecedentes históricos, características y objetivos. En J. Neffa (dir.), Desempleo, pobreza y políticas sociales. Fortalezas y debilidades del Plan Jefes y Jefas de Hogar Desocupados (pp. 71-184). Buenos Aires: Miño y Dávila Editores y CEIL-PIETTE Conicet.

Novick, M. (2001). Nuevas reglas de juego en Argentina: competitividad y actores sindicales. Los sindicatos frente a los procesos de transición política. En E. de la Garza (ed.), Los sindicatos frente a los procesos de transición política (pp. 25-46). Buenos Aires: Clacso. 
Nueva Mayoría. (2008). Cortes de rutas y vías públicas del 2008 ya superan los niveles registrados en la crisis 2001/2002. Recuperado de https://www.nuevamayoria.com/index.php?option=com_content\&task=view\&id $=587 \&$ Itemid $=30$

Nun, J. (1987). La teoría política y la transición democrática. En J. C. Portantiero, Ensayos sobre la transición democrática en la Argentina (pp. 15-56). Buenos Aires: Puntosur.

Nun, J. (1999). El futuro del empleo y la tesis de la masa marginal. Desarrollo Económico, 38(152), 985-1004. Recuperado de https://www.jstor.org/stable/3467265

Palomino, H., y Trajtemberg, D. (2006). Una nueva dinámica de las relaciones laborales y la negociación colectiva en la Argentina. Revista de Trabajo, 2(3), 47-68. Recuperado de https://www.trabajo.gob.ar/downloads/estadisti cas/2006n03_revistaDeTrabajo.pdf

Panigo, D., y Chena, P. (2011). Del neo-mercantilismo al tipo de cambio múltiple para el desarrollo. Los dos modelos de la post-Convertibilidad. En Ensayos en honor a Marcelo Diamand. Las raíces del nuevo modelo de desarrollo argentino y del pensamiento económico nacional. Buenos Aires: Miño y Dávila/CEIL-PIETTE/Universidad Nacional de Moreno.

Piana, R. S., y Baeza, N. S. (2013). Candidatos a medida. ¿Cómo se construyó el candidato que le ganó a los Kirchner? Revista de la Facultad de Derecho y Ciencias Políticas, 43(119), 773-800. Recuperado de https://www.revistas .upb.edu.co/index.php/derecho/article/view/2364/2107

Retamozo, M. (2009). Movimientos sociales. Subjetividad y acción de los trabajadores desocupados en Argentina. México: Flacso.

Retamozo, M., y Morris, M. B. (2015). Sindicalismo y política. La Central de Trabajadores de la Argentina en tiempos kirchneristas. Estudios Sociológicos, 33(97), 63-87. Recuperado de https://www.scielo.org.mx/scielo.php?scrip $\mathrm{t}=$ sci_arttext\&pid=S2448-64422015000100063\&lng=es\&tlng=es

Richards, D. G. (1997). Inflation, unemployment and distributional conflict in Argentina, 1984-90. The Journal of Development Studies, 34(2), 156-172. DOI: https://doi.org/10.1080/00220389708422515

Rocca Rivarola, M. D. (2009). Protagonista opositor, peronista desplazado: la Confederación General del Trabajo durante el gobierno de Raúl Alfonsín. Revista Mexicana de Ciencias Políticas y Sociales, 51(207), 137-154. DOI: https://dx.doi.org/10.22201/fcpys.2448492xe.2009.207

Schillagi, C. (2006). La obsesión excluyente: las movilizaciones sociales en torno a la cuestión de la (in) seguridad en Argentina durante el año 2004. Temas y Debates, (12), 109-137. Recuperado de https://www.temasydebates.u nr.edu.ar/index.php/tyd/article/viewFile/119/118

Schuster, F. L., y Pereyra, S. (2001). La protesta social en la Argentina democrática. Balance y perspectivas de una forma de acción política. En N. Giarracca (comp.), La protesta social en la Argentina. Transformaciones económicas y crisis social en el interior (pp. 41-63). Buenos Aires: Alianza Editorial.

Schuttenberg, M. (2011). La reconfiguración de las identidades "nacional populares": Los puentes discursivos para la inserción de tres tradiciones políticas en el espacio "transversal kirchnerista". Sociohistórica, (28), 41-73. Recuperado de https://www.scielo.org.ar/scielo.php?script=sci_arttext\&pid=S1852-16062011000100002

Schuster, F. L., Pérez, G. J., Peryra, S., Armesto, M., Armelino, M., García, A., ... Zipcioglu, P. (2006). Transformaciones de la protesta social en Argentina 1989-2003. Documentos de Trabajo, 48(1), 1-70. Recuperado de https://ww w.biblioteca.clacso.edu.ar/Argentina/iigg-uba/20100720094530/dt48.pdf

Senén González, C., y Haidar, J. (2009). Los debates acerca de la "revitalización sindical" y su aplicación en el análisis sectorial en Argentina. Revista Latinoamericana de Estudios del Trabajo 14(22), 5-31. Recuperado de https://w ww.alast.info/relet_ojs/index.php/relet/article/view/190

Souroujon, G. (2016). La relación entre la lógica religiosa y lo político en las democracias liberales. La sacralización política de Néstor Kirchner. Reflexión Política, 18(35), 16-27. DOI: https://doi.org/10.29375/01240781.2461

Stoessel, S. (2014). Giro a la izquierda en la América Latina del siglo XXI: Revisitando los debates académicos. Polis (Santiago), 13(39), 123-149. DOI: https://dx.doi.org/10.4067/S0718-65682014000300007

Svampa, M., y Pereyra, S. (2004). Entre la ruta y el barrio: la experiencia de las organizaciones piqueteras. Buenos Aires: Editorial Biblos. 
Svampa, M., y Viale, E. (2015). Mal desarrollo: la Argentina del extractivismo y el despojo.Buenos Aires: Katz.

Tagina, M. L. (2014). Las elecciones legislativas 2013 en Argentina. Revista Latinoamericana de Política Comparada, 45, 47-61. Recuperado de

Thompson, E. P. (1979). La economía moral de la multitud en la Inglaterra del siglo XVIII. Tradición, revuelta y consciencia de clase. Barcelona: Grijalbo.

Tilly, C. (1998). Procesos, contextos y transformaciones. Conflicto político y cambio social. En P. Ibarra y B. Tejerina (eds.) Los movimientos sociales (pp. 25-42). Madrid: Trotta.

Tóffoli, M. M. (2017). La “CGT de los excluidos”. La Confederación de Trabajadores de la Economía Popular (CTEP) (tesina de licenciatura en Sociología). UNLP, La Plata, Argentina.

Torre, J. C. (2005). La operación política de la transversalidad. El presidente Kirchner y el Partido Justicialista. Conferencia UTDT, noviembre de 2004. Recuperado de https://www.es.scribd.com/document/257578204/Torre-Juan-Carlos-la-Operacion-Politica-de-La-Trans versalidad-El-Presidente-Kirchner-y-El-Partido-Justicialista

Trajtemberg, D. (2009). El impacto de la determinación colectiva de salarios sobre la dispersión salarial. Trabajo, Ocupación y Empleo, Serie Estudios Laborales, (8), 123-148. Recuperado de https://www.trabajo.gob.ar/dow nloads/estadisticas/toe_08_completo.pdf

Trajtemberg, D. (2011). Instituciones laborales y desigualdad salarial: un análisis del efecto de la ampliación de la cobertura de la negociación colectiva entre 2003-2010. Ponencia presentada en el III Congreso Anual de Economía para el Desarrollo de la Argentina-AEDA, Buenos Aires.

Vázquez, M. (2013). En torno a la construcción de la juventud como causa pública durante el kirchnerismo: principios de adhesión, participación y reconocimiento. Revista Argentina de Estudios de Juventud, 1, 1-25. Recuperado de https://www.perio.unlp.edu.ar/ojs/index.php/revistadejuventud/article/view/2089

Vázquez, M., y Vommaro, P. (2012). La fuerza de los jóvenes: aproximaciones a la militancia kirchnerista desde La Cámpora. En Vamos las bandas. Organizaciones y militancia kirchnerista (pp. 149-174). Buenos Aires: Trilce.

Williams, R. (1980). Marxismo y literatura. Barcelona: Península.

Zapata, M. C. (2013). Toma de tierras en la ciudad de Buenos Aires: Un análisis de las causas estructurales que anunciaron el conflicto del Parque Indoamericano. Pampa (Santa Fe), (9), 45-71. Recuperado de https://www.s cielo.org.ar/scielo.php?script=sci_arttext\&pid=S2314-02082013000100003

\section{Notas}

[1] El proyecto "Los movimientos en el Estado y el Estado en movimiento", radicado en la Facultad de Humanidades y Ciencias de la Educación (UNLP) y el proyecto "Nuevos sujetos populares", radicado en el IdiHCS-CONICET (UNLP).

[2] Para un estudio de la CGT durante la transición democrática véase Rocca Rivarola (2009).

[3] Diferentes miradas sobre el proceso de partidización del peronismo pueden consultarse en Martuccelli y Svampa (1997), Mustapic (2002) y Levitsky (2005).

[4] Entre las organizaciones de derechos humanos se destacaron aquellas ligadas al pedido de juicio y castigo a los responsables de actos de represión ilegal, como Madres de Plaza de Mayo, Asamblea Permanente por los Derechos Humanos (APDH), Abuelas de Plaza de Mayo y el Centro de Estudios Legales y Sociales (CELS).

[5] El peronismo como una identidad plebeya se basa en la reivindicación de los orígenes obreros del peronismo, su representación de los sectores populares y la producción de una trama simbólica de expresión de lo subalterno.

[6] El estudio de los "piqueteros" produjo un conjunto de estudios en torno a la acción colectiva y la desocupación, entre ellos Auyero (2002) y Svampa y Pereyra (2004).

[7] Una emergencia disruptiva la protagonizaron los hijos e hijas de desaparecidos, exiliados y presos políticos que conformaron la agrupación Hijos por la Identidad y la Justicia, contra el Olvido y el Silencio (HIJOS)

[8] Según Cotarelo e Iñigo Carrera (2016): "En 2001, cuando culminó el ciclo ascendente de la rebelión iniciado en 1993, hubo seis huelgas generales $(21 / 3,8 / 6,19 / 7,8 / 8,13 / 12$ y 20/12); de ellas tres $(19 / 7,13 / 12$ y 20/12) fueron declaradas por las tres centrales sindicales (CGT -Daer, CGT-Moyano y CTA) y otra (21/3) por la CGT-Moyano y la CTA" (p. 88). 
[9] Esta orientación incluyó un posicionamiento geopolítico favorable a la integración sudamericana y en abierta oposición a los tratados de libre comercio promovidos por la administración de J.W. Bush. El gobierno de Kirchner se inscribió en el llamado giro a la izquierda, pink tide o populismo del siglo XXI (para una revisión del debate sobre el Giro a la izquierda véase Stoessel [2014]).

[10] La relación de dirigentes de movimientos sociales con el gobierno nacional desató una controversia sobre la naturaleza del vínculo entre actores, mientras algunos lo explicaban por la atención del gobierno a las demandas, otros lo interpretaron como cooptación de dirigentes. Para una revisión del debate véase Natalucci y Schuttenberg (2010).

[11] Para un análisis del conflicto del 2008 entre el gobierno y sectores empresariales puede consultarse la compilación de Aronskind y Vommaro (2010).

[12] Para un estudio más detallado de las organizaciones juveniles y su lugar en la contienda se puede consultar a Larrondo (2013) y a Vázquez (2013). Sobre la Cámpora, véase el trabajo de Vázquez y Vommaro (2012), y acerca de la Juventud Sindical Peronista véase Natalucci y Galimberti (2015).

[13] No obstante, el conflicto reapareció en torno a cuestiones habitacionales como la toma del Parque Indoamericano (Zapata, 2013).

[14] Según Morris (2018) entre marzo del 2011 y junio del 2015 se presentaron veintidós hechos de movilización convocados por las distintas centrales sindicales con alcance nacional.

* Artículo de reflexión

\section{Licencia Creative Commons CC BY 4.0}

Cómo citar este artículo: Retamozo, M., y Trujillo, L. (2018). Cambios estructurales y prácticas de movilización política en Argentina. Dos ciclos políticos en perspectiva (1989-2002 y 2003-2015). Papel Politico, 23(2). 1-19. https://doi.org/10.11144/Javeriana.papo23-2.cepm 